\title{
Sorafenib plus doxorubicin in advanced hepatocellular carcinoma patients: hope or hype?
}

\author{
Kit Shing ${ }^{1}$, Gerry Kwok ${ }^{1}$, Joanne Chiu ${ }^{1}$, Tan To Cheung ${ }^{2}$, Thomas Yau ${ }^{1}$ \\ ${ }^{1}$ Department of Medicine, Queen Mary Hospital, University of Hong Kong, Hong Kong, China; ${ }^{2}$ Department of Surgery, Queen Mary Hospital, \\ University of Hong Kong, Hong Kong, China \\ Correspondence to: Dr. Thomas Yau. Room 415, 4/Floor Professorial Block, 102 Pokfulam Road, Hong Kong, China. Email: the@netvigator.com. \\ Comment on: Abou-Alfa GK, Shi Q, Knox JJ, et al. Assessment of Treatment With Sorafenib Plus Doxorubicin vs Sorafenib Alone in Patients With \\ Advanced Hepatocellular Carcinoma: Phase 3 CALGB 80802 Randomized Clinical Trial. JAMA Oncol 2019;5:1582-8.
}

Submitted Jul 13, 2020. Accepted for publication Jul 22, 2020.

doi: 10.21037/atm-2020-130

View this article at: http://dx.doi.org/10.21037/atm-2020-130

More than a decade ago, sorafenib changed the treatment landscape of advanced hepatocellular carcinoma (HCC) by showing an overall survival (OS) benefit compared with placebo (1). The reported median 2.8-month OS benefit was encouraging, but low response rates and the lack of predictive biomarkers meant that significant clinical benefit remains limited and confined to patients with preserved liver function. Since a fraction of HCC are chemo-sensitive, investigators have attempted to combine chemotherapy with sorafenib to enhance treatment efficacy. Doxorubicin and sorafenib was tolerable and safe at dose finding, and have been tested in a phase 3 randomized controlled trial by Abou-Alfa et al. $(2,3)$. This study compares the combination with sorafenib to address important questions regarding efficacy and safety.

The multicentered alliance-led study randomized 356 untreated patients with histologically proven advanced HCC at 1:1 ratio to sorafenib and doxorubicin $(\mathrm{n}=180) v s$. sorafenib alone $(\mathrm{n}=176)$. With a target recruitment of 480 patients, the study was prematurely terminated in 2015 for futility at interim analysis. It had stringent criteria for study entry: including an Eastern Cooperative Oncology Group performance status of 0-1, Child-Pugh Class A liver function, adequate hematological parameters, and adequate left ventricular systolic function defined as $45 \%$ and above.

Baseline characteristics were similar between the study arms with approximately $58 \%$ and $57 \%$ contributed by metastatic disease in the respective arms. Most patients were Caucasian (67\%), explaining the low rates of hepatitis B (8.9\% and $9.7 \%$ respectively) as compared with hepatitis $\mathrm{C}$ etiology ( $21 \%$ and $18 \%$ ). However, the hepatitis status of 167 patients,
$45 \%$ of the doxorubicin plus sorafenib arm and $48.9 \%$ of the sorafenib arm, nearly half of the study population, were unknown. Sorafenib was given at $400 \mathrm{mg}$ twice daily for both arms while doxorubicin was dosed at $60 \mathrm{mg} / \mathrm{m}^{2}$ every 3 weeks up to an accumulative dose of $360 \mathrm{mg} / \mathrm{m}^{2}$. Median dose of doxorubicin was $237.5 \mathrm{mg}$ (range, $0-1,036 \mathrm{mg}$ ) over a median of 3 cycles, while median sorafenib doses were $433 \mathrm{mg}$ (range, 19-895 mg) and $495 \mathrm{mg}$ (range, 38-994 mg) respectively. The primary endpoint of median OS was 9.3 months (95\% CI, 7.3-10.8 months) for sorafenib plus doxorubicin and 9.4 months (95\% CI, 7.3-12.9 months) for sorafenib alone (hazard ratio, 1.05; 95\% CI, 0.83-1.31). Progression free survival was likewise no different between the study arms (median $4.0 \mathrm{vs}$. 3.7 months; hazard ratio, 0.93 ; $95 \%$ CI, $0.75-1.16$ ).

This study reiterates the marginal benefit of chemotherapy in HCC and confirms the lack of clinical benefit over sorafenib when given in combination $(2,4)$. Numerous chemo-resistant mechanisms in HCC have been documented: including recurrent TP53 mutations and P-glycoprotein expression $(5,6)$. Further, treatment of human HCC cell lines with doxorubicin led to the rapid emergence of resistant clones which upregulate $\mathrm{P}$-glycoprotein and epithelial-to-mesenchymal marker SNAIL (7). Consistently, adding doxorubicin did not increase response rates $(\mathrm{P}=0.52)$, but increased rates of grade 3-4 neutropenia (36.8\%) and thrombocytopenia $(17.5 \%)$. These toxicities likely contributed to cycle delays, dose reductions, and compromised efficacy. Clinically relevant adverse events related to doxorubicin in this population of background liver disease such as infection, 
neutropenic fever, bleeding, and hepatic decompensation were not reported. Antiviral medication was also not reported for hepatitis B patients. Grade 3-4 cardiac toxicity and decreases in left ventricular ejection fraction occurred in $3.0 \%$ and $4.8 \%$ of patients on doxorubicin respectively, raising questions regarding the safety and tolerability of this combination.

Recently, next generation kinase inhibitors and immune checkpoint inhibitors have shown efficacy in $\operatorname{HCC}(8,9)$. These studies not only address later line treatment options after sorafenib, but in the case of immune checkpoint blockade, have charted new treatment opportunities for patients with more advanced liver disease that are contraindicated for multi-kinase inhibitors. Although the current trial has failed to demonstrate benefit with the addition of doxorubicin to sorafenib, studies of cytotoxicchemotherapy and anti-PD-1 combinations may still be of relevance to immunogenic cell death and potentiation of anti-tumor immunity (10).

\section{Acknowledgments}

Funding: None.

\section{Footnote}

Provenance and Peer Review: This article was commissioned by the editorial office, Annals of Translational Medicine. The article did not undergo external peer review.

Conflicts of Interest: All authors have completed the ICMJE uniform disclosure form (available at http://dx.doi. org/10.21037/atm-2020-130). The authors have no conflicts of interest to declare.

Ethical Statement: The authors are accountable for all aspects of the work in ensuring that questions related to the accuracy or integrity of any part of the work are appropriately investigated and resolved.

Open Access Statement: This is an Open Access article distributed in accordance with the Creative Commons Attribution-NonCommercial-NoDerivs 4.0 International License (CC BY-NC-ND 4.0), which permits the noncommercial replication and distribution of the article with the strict proviso that no changes or edits are made and the original work is properly cited (including links to both the formal publication through the relevant DOI and the license).
See: https://creativecommons.org/licenses/by-nc-nd/4.0/.

\section{References}

1. Llovet JM, Ricci S, Mazzaferro V, et al. Sorafenib in advanced hepatocellular carcinoma. $\mathrm{N}$ Engl J Med 2008;359:378-90.

2. Abou-Alfa GK, Shi Q, Knox JJ, et al. Assessment of Treatment With Sorafenib Plus Doxorubicin vs Sorafenib Alone in Patients With Advanced Hepatocellular Carcinoma: Phase 3 CALGB 80802 Randomized Clinical Trial. JAMA Oncol 2019;5:1582-8.

3. Richly H, Schultheis B, Adamietz IA, et al. Combination of sorafenib and doxorubicin in patients with advanced hepatocellular carcinoma: results from a phase I extension trial. Eur J Cancer 2009;45:579-87.

4. Asghar U, Meyer T. Are there opportunities for chemotherapy in the treatment of hepatocellular cancer? J Hepatol 2012;56:686-95.

5. Ng IO, Liu CL, Fan ST, et al. Expression of P-glycoprotein in hepatocellular carcinoma. A determinant of chemotherapy response. Am J Clin Pathol 2000;113:355-63.

6. Cancer Genome Atlas Research Network. Electronic address wbe, Cancer Genome Atlas Research N.

Comprehensive and Integrative Genomic Characterization of Hepatocellular Carcinoma. Cell 2017;169:1327-41.e23.

7. Buschauer S, Koch A, Wiggermann P, et al. Hepatocellular carcinoma cells surviving doxorubicin treatment exhibit increased migratory potential and resistance to doxorubicin re-treatment in vitro. Oncol Lett 2018;15:4635-40.

8. Bruix J, Qin S, Merle P, et al. Regorafenib for patients with hepatocellular carcinoma who progressed on sorafenib treatment (RESORCE): a randomised, double-blind, placebo-controlled, phase 3 trial. Lancet 2017;389:56-66.

9. El-Khoueiry AB, Sangro B, Yau T, et al. Nivolumab in patients with advanced hepatocellular carcinoma (CheckMate 040): an open-label, non-comparative, phase 1/2 dose escalation and expansion trial. Lancet 2017;389:2492-502.

10. Emens LA, Middleton G. The interplay of immunotherapy and chemotherapy: harnessing potential synergies. Cancer Immunol Res 2015;3:436-43.

Cite this article as: Shing K, Kwok G, Chiu J, Cheung TT, Yau T. Sorafenib plus doxorubicin in advanced hepatocellular carcinoma patients: hope or hype? Ann Transl Med 2020;8(24):1695. doi: 10.21037/atm-2020-130 